ARTICLE

\title{
Robust and efficient hydrogenation of carbonyl compounds catalysed by mixed donor $\mathrm{Mn}(\mathrm{I})$ pincer complexes
}

\author{
Wenjun Yang (1) ${ }^{1}$, Ivan Yu. Chernyshov², Robin K. A. van Schendel', Manuela Weber ${ }^{3}$, Christian Müller ${ }^{3}$,
} Georgy A. Filonenko (i) ${ }^{1 凶} \&$ Evgeny A. Pidko (i) ${ }^{1 凶}$

Any catalyst should be efficient and stable to be implemented in practice. This requirement is particularly valid for manganese hydrogenation catalysts. While representing a more sustainable alternative to conventional noble metal-based systems, manganese hydrogenation catalysts are prone to degrade under catalytic conditions once operation temperatures are high. Herein, we report a highly efficient $M n(I)-C N P$ pre-catalyst which gives rise to the excellent productivity (TOF ${ }^{\circ}$ up to $41000 \mathrm{~h}^{-1}$ ) and stability (TON up to 200 000) in hydrogenation catalysis. This system enables near-quantitative hydrogenation of ketones, imines, aldehydes and formate esters at the catalyst loadings as low as 5-200 p.p.m. Our analysis points to the crucial role of the catalyst activation step for the catalytic performance and stability of the system. While conventional activation employing alkoxide bases can ultimately provide catalytically competent species under hydrogen atmosphere, activation of $\mathrm{Mn}(\mathrm{I})$ pre-catalyst with hydride donor promoters, e.g. $\mathrm{KHBEt}_{3}$, dramatically improves catalytic performance of the system and eliminates induction times associated with slow catalyst activation.

\footnotetext{
${ }^{1}$ Inorganic Systems Engineering group, Department of Chemical Engineering, Faculty of Applied Sciences, Delft University of Technology, Van der Maasweg 9, 2629 HZ Delft, The Netherlands. ${ }^{2}$ TheoMAT Group, ChemBio cluster, ITMO University, Lomonosova 9, St, Petersburg 191002, Russia. ${ }^{3}$ Institute of

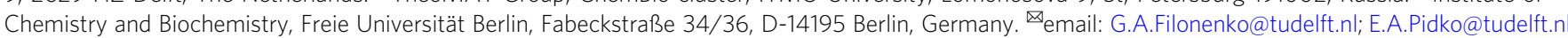


C atalytic hydrogenation of carbonyl derivatives with molecular hydrogen is an essential technique for the production of bulk and fine chemicals ${ }^{1}$. The state of the art in hydrogenation catalysis to this date is laid down by well-defined noble metal complexes based on ruthenium, iridium, and rhodium $^{2,3}$. However, the requirements for more sustainable hydrogenation processes recently initiated a search for earthabundant, inexpensive $3 d$ metals that can replace their noble counterparts $^{4-7}$. In this search, the catalysts based on highly biocompatible and abundant $\mathrm{Mn}$ metal became particularly prominent $^{8-13}$.

Manganese-based hydrogenation catalysis has become a subject of intense research since 2016, largely set off by the pioneering work of Beller and coworkers ${ }^{14}$. An Mn pincer complex A (Fig. 1) promoted hydrogenation of ketones, aldehydes and nitriles operating at $1-3 \mathrm{~mol} \%$ loading at $60-120^{\circ} \mathrm{C}$ and $10-50$ bar $\mathrm{H}_{2}$ pressure. Following the initial reports, the field of hydrogenation with $\mathrm{Mn}$ was extended to several prominent ligand platforms ${ }^{9,10,15-27}$.

Specifically, in addition to aminopincer ligands, the diamino triazine-based pincers $\mathbf{B}$ and lutidine-derived $\mathrm{PNN}$ pincer $\mathbf{C}$ ligands were introduced to $\mathrm{Mn}$-catalyzed hydrogenations by the groups of Kempe ${ }^{28}$ and Milstein ${ }^{29}$, and saw further improvement in recent years ${ }^{30}$. In addition to pincer ligands, several bidentate ligands have been employed in Mn catalysis. These include PN aminophosphines developed by our group (D, Fig. 1) ${ }^{31}$, diphosphines $\mathbf{E}$ reported by the groups of Kirchner ${ }^{32}$ and García ${ }^{33}$. The most recent addition to this set was reported by Sortais and coworkers who described catalyst $\mathbf{F}$ (Fig. 1) based on a bidentate ligand containing phosphine and N-heterocyclic carbene (NHC) donors. Together with catalyst $\mathbf{B}$, complex $\mathbf{F}$ is one of the most potent $\mathrm{Mn}$ ketone hydrogenation catalysts requiring ca. $0.1 \mathrm{~mol} \%$ catalyst loading for operation ${ }^{34}$.

The activity of $\mathrm{Mn}$ catalysts is generally lower than that of noble metal catalysts with majority of Mn-catalyzed hydrogenations requiring relatively high catalyst loadings of $0.1-5 \mathrm{~mol} \%-\mathrm{a}$ feature that strongly limits their practical utility. We recently demonstrated that reliance on such high metal loadings in Mn catalysis might stem from the limited stability of Mn pre-catalysts, most noticeable when Mn loadings are low ${ }^{35}$. Namely, we noted that $\mathrm{Mn}(\mathrm{I})-\mathrm{NHC}$ complexes featuring aminocarbene " $\mathrm{CN}$ " bidentate ligands were highly competent hydride transfer catalysts at low reaction temperatures and high metal loadings, but a rapid catalyst degradation took place upon even marginal increase of reaction temperatures or reduction of catalyst loading $<100$ p.p.m. with respect to reduction substrate ${ }^{35}$. Addressing the catalyst stability in this work, we developed an active and highly stable $\mathrm{Mn}(\mathrm{I})$ catalyst that can promote hydrogenation reactions at catalyst loadings as low as 5 parts per million. Responsible for such performance is the tridentate CNP ligand platform (Fig. 1) that exhibits highly unusual phosphine hemilability, and enables catalyst activation pathways unavailable for known Mn catalysts.

\section{Results}

Synthesis and hydrogenation activity of 3. Our initial synthetic effort was targeted at addressing the stability of manganese catalysts utilizing bidentate "CN" ligands (1, Fig. 2) by extending the ligand with additional phosphine donor arm. This extension of $\mathrm{CN}$ ligand 1 was done via a straightforward reductive amination producing the air-stable $\mathbf{L 1}$ in $81 \%$ yield (Fig. 2). The $\mathbf{L 1}$ can undergo complexation to form 3 by a one-pot reaction involving pre-coordination to $\mathrm{Mn}(\mathrm{CO})_{5} \mathrm{Br}$ followed by the base-assisted formation of the NHC complex (Fig. 2). Analytically pure MnCNP complex 3 was isolated in 51\% yield with its identity confirmed by NMR and IR spectroscopy, and elemental analysis (see Supplementary Information).

The IR spectrum of 3 features three strong bands at 2021, 1943, and $1919 \mathrm{~cm}^{-1}$ consistent with the presence of three carbonyl ligands in a facial arrangement within the cationic complex ${ }^{15}$. The characteristic ${ }^{31} \mathrm{P}$ resonances in NMR spectrum of 3 appear at $\delta=37.5(\mathrm{~s}),-144.4$ (hep, ${ }^{1} J_{\mathrm{FP}} 712.8 \mathrm{~Hz}$ ) p.p.m. confirming the coordination of the phosphine donor arm and the presence of the hexafluorophosphate anion in 3 . Finally, the ${ }^{13} \mathrm{C}$ NMR revealed resonances at $217.7,215.5,213.9$, and 187.0 p.p.m. confirming the presence of three inequivalent carbonyl ligands and an Mn-bound NHC ligand.

Complex $\mathbf{3}$ is a potent and stable precatalyst for ketone hydrogenation. We screened its performance in hydrogenation of acetophenone benchmark substrate in various solvents at different $\mathrm{H}_{2}$ pressures (see Supplementary Tables 1 and 2), and found the $\mathrm{H}_{2}$ pressure of 50 bar and dioxane solvent to be optimal for performance. This combination was further used to evaluate the impact of reaction temperature and catalyst loadings on the hydrogenation yield. The results listed in Table 1 indicate that the quantitative hydrogenation of acetophenone to the corresponding alcohol can be obtained with catalyst loadings as low as 50 p.p.m. at $60{ }^{\circ} \mathrm{C}$ (Table 1 , entries $1-3$ ). Importantly, catalyst 3 tolerates elevated reaction temperatures of 80 and $100{ }^{\circ} \mathrm{C}$, that marks a significant improvement of thermal stability over the parent $\mathrm{CN}$ bidentate that rapidly degraded as the temperatures were elevated over $70^{\circ} \mathrm{C}$ (ref. ${ }^{35}$ ). Even at $100^{\circ} \mathrm{C}$ hydrogenations with 3 led to quantitative yields requiring only 50 p.p.m. catalyst loading (entries 5 and 6). At low catalyst loading conditions, the activity of $\mathbf{3}$ compares favorably with a related MnPNP system A (ref. ${ }^{14}$;

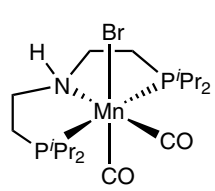

A

Beller, 2016

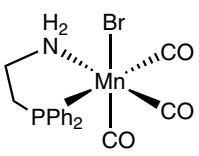

D

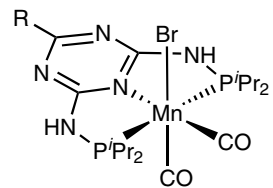

B

Kempe, 2016 $\left(\mathrm{R}=\mathrm{NH}-\mathrm{C}_{3} \mathrm{H}_{5}\right)$

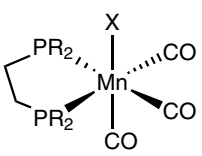

E

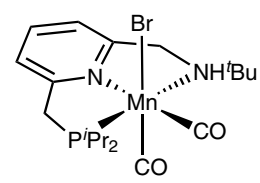

C

Milstein, 2017

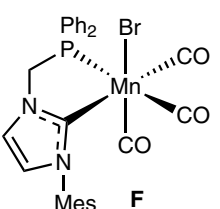

Sortais, 2019

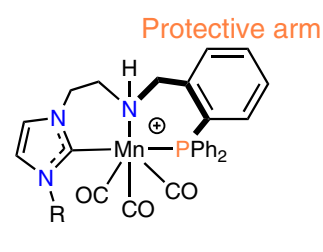

Mn-CNP

this work

Pidko, 2017 García, 2018 (X = OTf, $\mathrm{R}={ }^{i} \mathrm{Pr}$ )

Kirchner, $2018(X=B r, R=n-P r)$

Fig. $1 \mathrm{Mn}$ complexes. Selected examples of Mn hydrogenation catalysts and the complex used in this work. 


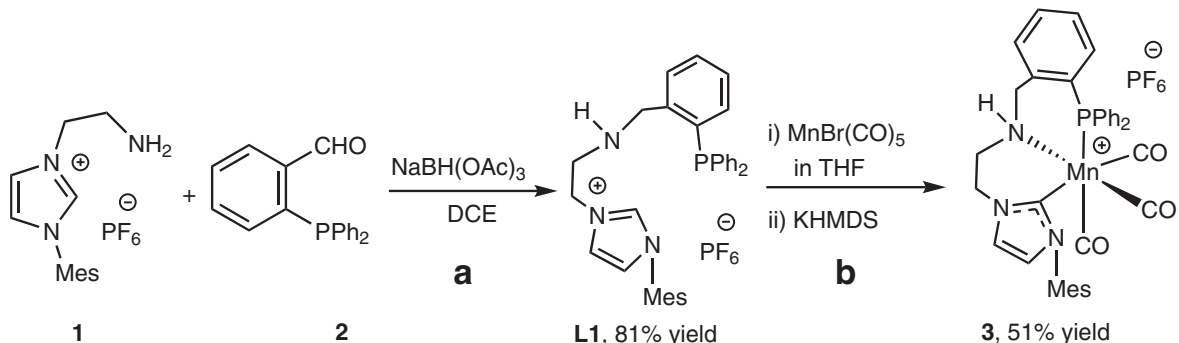

Fig. 2 Synthesis of $\mathbf{M n}(\mathbf{I})$ complex 3. a Conditions: 1 ( $8 \mathrm{mmol}), \mathbf{2}$ (1 eq.), $\mathrm{NaBH}(\mathrm{OAc})_{3}$ (2.5 eq.), DCE (20 mL), rt, 12 h. b Conditions: (i) L1 (0.5 mmol), $\operatorname{MnBr}(\mathrm{CO})_{5}$ (1 eq.), THF ( $\left.5 \mathrm{~mL}\right), 50^{\circ} \mathrm{C}$ rt, $12 \mathrm{~h}$; (ii) KHMDS (1.1 eq.), rt, $3 \mathrm{~h}$.

Table 1 Manganese-catalyzed hydrogenation of acetophenone ${ }^{a}$.

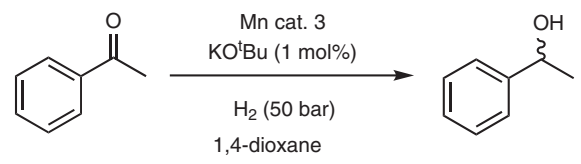

\begin{tabular}{|c|c|c|c|c|}
\hline Entry & Cat. (mol\%/p.p.m.) & $T\left({ }^{\circ} \mathrm{C}\right)$ & $t(h)^{b}$ & Yield (\%)c \\
\hline 1 & $3(0.02 / 200)$ & 60 & 16 & 99 \\
\hline 2 & $3(0.01 / 100)$ & 60 & 16 & 99 \\
\hline 3 & $3(0.005 / 50)$ & 60 & 46 & 99 \\
\hline 4 & $\mathbf{A}(0.02 / 200)$ & 80 & 24 & 67 \\
\hline 5 & $3(0.02 / 200)$ & 80 & 3 & 99 \\
\hline 6 & $3(0.02 / 200)$ & 100 & 1 & 99 \\
\hline 7 & $3(0.01 / 100)$ & 100 & 3 & 99 \\
\hline 8 & $3(0.005 / 50)$ & 100 & 28 & 99 \\
\hline 9 & $3(0.0025 / 25)$ & 100 & 28 & 87 \\
\hline
\end{tabular}

entries 4 and 5). The hydrogenation with 3 at 200 p.p.m. loading at $80^{\circ} \mathrm{C}$ is complete within $3 \mathrm{~h}$, whereas catalyst A (Fig. 1) provides $67 \%$ conversion in $24 \mathrm{~h}$ under identical conditions.

The analysis of reaction progress using the $\mathrm{H}_{2}$ uptake measurements (see Supplementary Information) reveals that catalyst deactivation at elevated temperatures is only pronounced at very low catalyst loadings. Namely, for the reaction at $100^{\circ} \mathrm{C}$ (entries 6-9, Table 1), full ketone conversion can be reached with 50 p.p.m. of 3, whereas at 25 p.p.m. the reaction does not proceed beyond $87 \%$ conversion level regardless of the reaction times employed (see Supplementary Fig. 38). Having observed that the introduction of a protective phosphine arm in complex 3 has markedly increased the catalyst thermal stability, we sought to improve the performance of $\mathbf{3}$ further. Apart from stability per se, we aimed at improving catalyst activation protocol that is an integral parameter to any catalytic system.

Mechanistic analysis. Catalyst activation, at large, is the reactivity pattern resulting in the generation of the active catalyst species. Similar to most bifunctional hydrogenation catalysts ${ }^{4-13}$, our initial approach to catalyst activation involved the reaction of $\mathbf{3}$ with excess strong $\mathrm{KO}^{t} \mathrm{Bu}$ alkoxide base followed by $\mathrm{H}_{2}$ to form the catalytically active $\mathrm{Mn}-\mathrm{H}$ moiety (Fig. 3a). Tracking this transformation with the IR spectroscopy we observed a rapid and clean conversion of $\mathbf{3}$ upon reaction with $\mathrm{KO}^{t} \mathrm{Bu}$ (Fig. $3 \mathrm{~b}$ ) into the amido complex 4. Notably, all three CO ligands were retained within 4 as follows from the presence of new bands at 1989, 1901, and $1885 \mathrm{~cm}^{-1}$. The resonance of phosphine donor in 4 was slightly shifted upfield to $\delta=33.6$ p.p.m. in ${ }^{31} \mathrm{P}$ NMR compared to the initial cationic complex 3 ( $\delta=37.7$ p.p.m.). At the same time complex 4, as well as its parent complex 3 exhibited restricted mesityl group rotation dynamics evidenced by the loss of equivalency between ortho-methyl substituents of the mesityl group on the NMR timescales-a typical feature of $\mathrm{Mn}(\mathrm{I})-\mathrm{NHC}$ complexes ${ }^{35}$.

Complex 4 was stable in THF for up to $24 \mathrm{~h}$ and could be isolated as microcrystalline solid in $70 \%$ yield. The analysis of solid-state crystal structure of $\mathbf{4}$ confirmed the facial configuration of the tridentate CNP ligand implied by the NMR and IR spectral data (Fig. 3c). Remarkably, the single-crystal X-ray diffraction results revealed a highly unusual $\mathrm{P}$-donor binding geometry in 4 with $\mathrm{N}-\mathrm{Mn}-\mathrm{P}$ angle of mere $67.4^{\circ}$. For comparison, the corresponding valent angles in related MnPNP pincer complexes are $>80^{\circ}$ (refs. ${ }^{28-30}$ ), indicating a significant coordination strain in complex 4 featuring the fac-bound CNP ligand.

Complex 4 reacts with $\mathrm{H}_{2}$ gas upon heating, resulting in a loss of one of the $\mathrm{CO}$ ligands and the formation of isomers of a manganese hydride pincer complex 5 (Fig. 3). However, this reaction is particularly slow and proceeds to ca. $24 \%$ conversion of the starting complex 4 at $50^{\circ} \mathrm{C}$ over $12 \mathrm{~h}$ under 3 bar $\mathrm{H}_{2}$ pressure. The reaction gives rise to two new doublet resonances in ${ }^{1} \mathrm{H}$ NMR spectrum at -3.46 and -3.49 p.p.m. with ${ }^{2} J_{\mathrm{PH}}=60.0$ and $68.0 \mathrm{~Hz}$, respectively (Fig. 3d), corresponding to two isomers of dicarbonyl Mn-H species 5 with phosphine arm bound to $\mathrm{Mn}$ center. DFT analysis suggests that the main feature distinguishing these isomers is the respective positions of the axial carbonyl and hydride ligands relative to the meridionally bound CNP pincer 
a

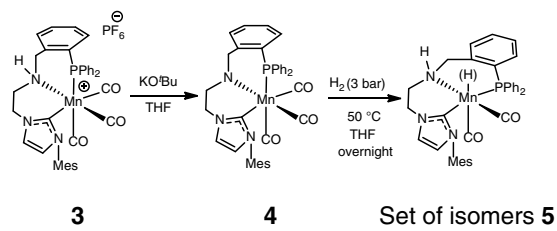

b

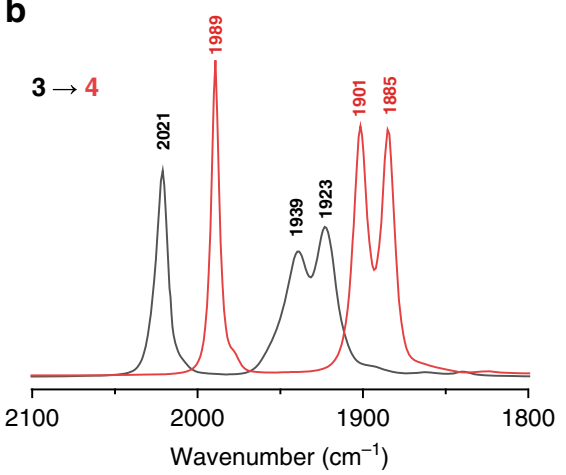

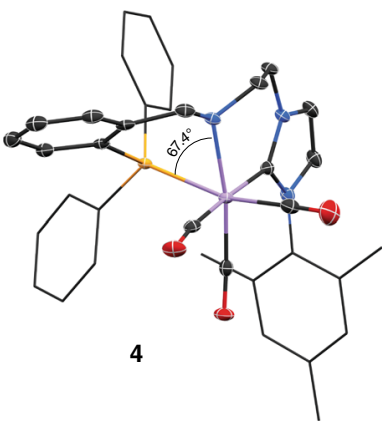

d

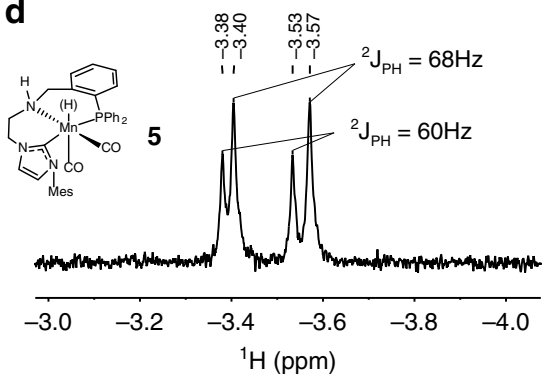

Fig. 3 Activation and reactivity of complex 3. a Generation of complex $\mathbf{5}$ upon reaction with $\mathrm{H}_{2}$ ( 3 bar). b IR spectra of complex $\mathbf{3}$ (black) and in situ generated complex $\mathbf{4}$ (red) recorded in THF at $25^{\circ} \mathrm{C}$. c Molecular structure of complex $\mathbf{4}$ in the crystal with thermal ellipsoids drawn at $50 \%$ probability. d Hydride region of ${ }^{1} \mathrm{H}$ NMR $\left(T H F-d_{8}\right.$ ) spectra of in situ generated isomers of complex $\mathbf{5}$ (see Supplementary Fig. 19 for full spectra and analysis of isomers of 5, conversion of 4-5 estimated at $24 \%$ by ${ }^{1} \mathrm{H}$ NMR).

(see Supplementary Figs. 40 and 41 for all analyzed structures), and allows ruling out the generation of $f a c$ isomers of the same composition.

From catalysis standpoint, the formation of Mn hydride species is generally accepted as a prerequisite for entering the hydro-

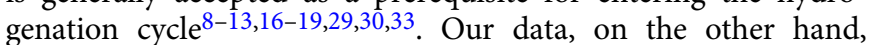
indicated that the $\mathrm{Mn}-\mathrm{H}$ formation from 4 is slow and requires the irreversible loss of one CO ligand. Seeking for an alternative to the sluggish direct $\mathrm{H}_{2}$ activation, we found that the reaction of precatalyst 3 with 2.5 equiv. of the $\mathrm{KBHEt}_{3}$ hydride donor can also generate a $\mathrm{Mn}-\mathrm{H}$ species in an instant manner. In THF- $d_{8}$ at room temperature the reaction of 3 with $\mathrm{KBHEt}_{3}$ readily yields a reaction mixture containing $69 \%$ of the amido complex 4 with remainder comprised of new manganese hydride species 6 (Fig. 4a) that exist as a mixture of isomers. Unlike Mn hydride complex 5 observed in alkoxide-based activation protocol, species 6 features a free phosphine arm. The latter is evidenced by the appearance of the singlet resonances at $\delta=-16.2$ and -16.6 p.p. $\mathrm{m}$. in ${ }^{31} \mathrm{P} \mathrm{NMR}$. As in the case of $\mathbf{5}$, complex $\mathbf{6}$ exists as two isomers distinguished by ${ }^{31} \mathrm{P}$ resonances and those of hydride ligands appearing as singlets at $\delta=-3.92$ and -4.40 p.p.m. in ${ }^{1} \mathrm{H}$ NMR spectrum. Similar to the case of 5, DFT analysis suggests that complex 6 exists with meridionally bound CNP ligand and hydride ligands occupying axial position within the complex (see Supplementary Fig. 41). Species 6, being stable in solution for several hours, slowly convert to $\mathbf{5}$ as confirmed by in situ solution IR studies and NMR data depicted in Fig. 4a (see Supplementary Figs. 22-25 and 28 for full spectra).

An unusual feature of the CNP ligand, responsible for the formation of complex $\mathbf{6}$ is the apparent hemilabile nature of phosphine donor arm in MnCNP precatalyst. The phenomenon of ligand hemilability is often employed to rationalize reactivity of organometallic compounds ${ }^{36-41}$, especially in the context of hybrid and multidentate ligands ${ }^{42-44}$. Invoked mainly for labile donor groups, e.g., oxygen or nitrogen ${ }^{43}$, hemilability is scarce for phosphine donors in general ${ }^{45-47}$ and for manganese phosphines in particular ${ }^{48,49}$. In case on MnCNP complexes, generation of hydride complex $\mathbf{6}$ presents an attractive activation protocol for 3 . Unlike the sluggish base-assisted activation with molecular $\mathrm{H}_{2}$, the reaction with $\mathrm{KBHEt}_{3}$ proceeds instantly at room temperature and does not require CO ligand dissociation steps. The hydride species produces in such manner are catalytically competent and readily react with ketone substrates. Our stoichiometric studies indicate the higher reactivity of $\mathbf{6}$ toward ketones, compared to 5 . The stepwise introduction of a stoichiometric amount of acetophenone to the mixture containing $\mathbf{5}$ and $\mathbf{6}$ leads to a rapid disappearance of the resonances of $\mathbf{6}$, highlighting it as a more competent hydride donor (see Supplementary Fig. 29).

We found that the improved activation protocol has a profound effect on the hydrogenation kinetics. Monitoring the hydrogenation kinetics, we could confirm that the use of $\mathrm{KHBEt}_{3}$ promoter at $60^{\circ} \mathrm{C}$ and 50 bar $\mathrm{H}_{2}$ pressure significantly reduces the hydrogenation onset time compared to the $\mathrm{KO}^{t} \mathrm{Bu}$-promoted catalysis (Fig. 4b). While the activation of the MnCNP precatalyst with the alkoxide base resulted in ca. $15 \mathrm{~min}$ induction period, the $\mathrm{KHBEt}_{3}$ treatment eliminated this lag time. Furthermore, the more selective precatalyst activation with the borohydride promotor resulted in a nearly threefold increase of the hydrogenation rate. We suggest this improvement to stem from an efficient catalyst activation protocol that allows for facile generation of competent hydride species $\mathbf{5}$ and $\mathbf{6}$, thus ensuring the ability of $\mathrm{Mn}$ precatalyst to enter the catalytic cycle immediately. As our data depicted in Fig. 4a suggested that both 5 and $\mathbf{6}$ are exhibiting the hydride transfer reactivity upon the contact with acetophenone, we further attempted to observe the outcome of the catalytic turnover on the relative composition of the reaction mixture using NMR spectroscopy. Results of this experiment are presented in Fig. 4a. We observed that hydrogenation of acetophenone substrate with reaction mixtures containing predominantly hydride species $\mathbf{6}$ results in the accumulation of the dicarbonyl complex 5. While suggesting that the catalytic turnover involving solely species $\mathbf{6}$ and associated ligand hemilability is possible, gradual accumulation of 5 in the course of several catalytic turnovers suggests that the 
a

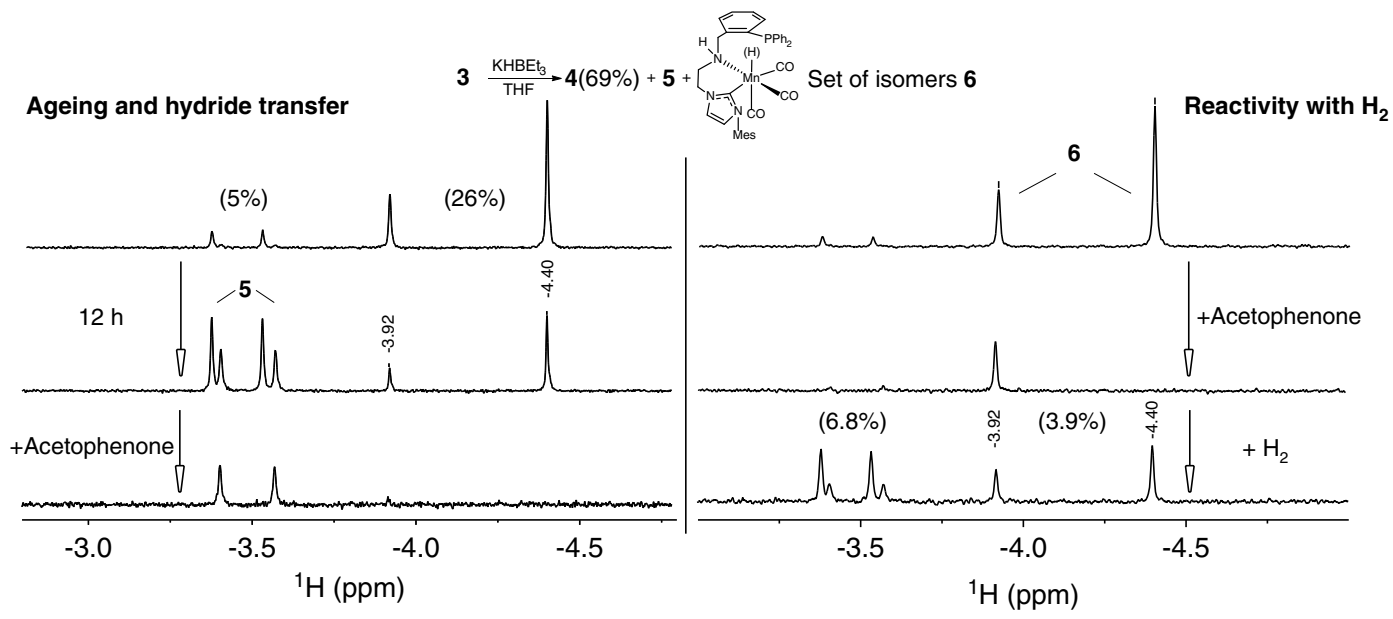

b

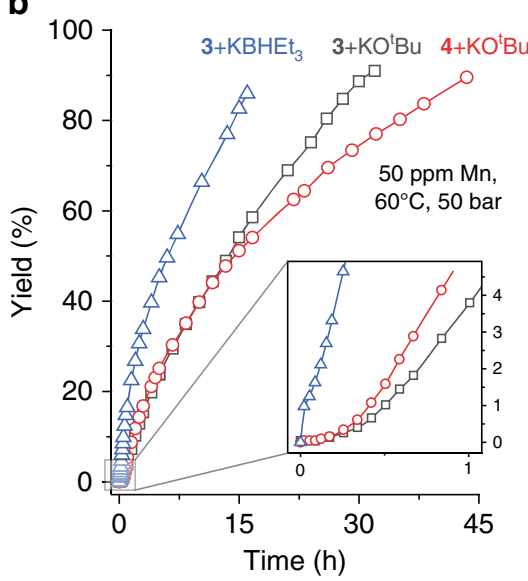

c

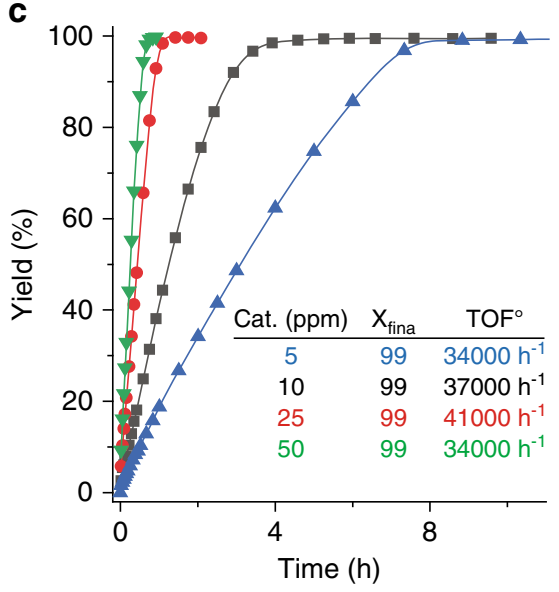

d

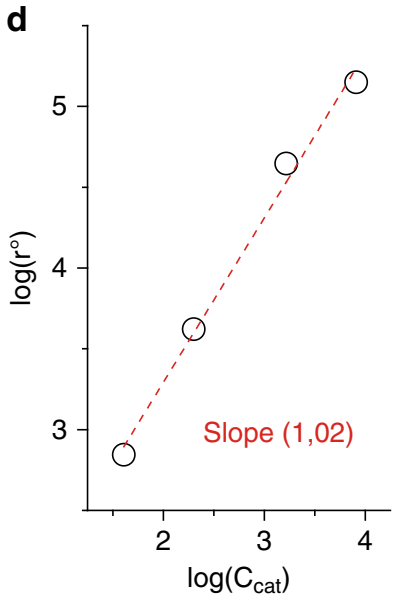

Fig. 4 Catalyst activation with $\mathrm{KBHEt}_{3}$ and corresponding catalytic performance. a ${ }^{1} \mathrm{H} N M R$ spectra of the hydride region for $\mathrm{KHBEt}_{3}$ activated complex 3. Left panel shows slow conversion of $\mathbf{6}$ to complex $\mathbf{5}$ and subsequent reactivity with acetophenone; right panel shows reactivity of species $\mathbf{6}$ with acetophenone and regeneration of reactive hydride species in $\mathrm{H}_{2}$ atmosphere (see Supplementary Figs. 32-35 for details); relative content of hydride species indicated in percent units of total Mn. $\mathbf{b}$ Kinetic traces for the hydrogenation of acetophenone with complexes $\mathbf{3}$ and $\mathbf{4}$ in the presence of $1 \mathrm{~mol} \%$ $\mathrm{KO}^{\mathrm{t}} \mathrm{Bu}$ or $1 \mathrm{~mol} \% \mathrm{KHBEt}_{3}$ promoters at $60^{\circ} \mathrm{C}, 50$ bar $\mathrm{H}_{2}$, and 50 p.p.m. Mn loading. c Kinetic traces of acetophenone hydrogenation with 3 at different catalyst loading. Conditions: 50 bar $\mathrm{H}_{2}, 120^{\circ} \mathrm{C}, 12.5 \mathrm{mmol}$ substrate, 1 mol\% of $\mathrm{KHBEt}_{3}$, catalyst loading indicated on the graph. $\mathbf{d}$ Double logarithmic plot for reaction order analysis with respect to catalyst concentration for the data plotted in $\mathbf{c}$.

\section{Table 2 Manganese-catalyzed hydrogenation of acetophenone with $\mathrm{KBHEt}_{3}$ promotora.}

\begin{tabular}{lllll} 
Entry & $\begin{array}{l}\text { Cat. } \mathbf{3}(\mathbf{m o l} \% / \mathbf{p . p} . \\
\mathbf{m .})\end{array}$ & $\left.\mathbf{T} \mathbf{(}^{\mathbf{O}} \mathbf{C}\right)$ & $\mathbf{t}(\mathbf{h})^{\mathbf{b}}$ & Yield (\%)c \\
\hline 1 & $0.005 / 50$ & 100 & 4 & 99 \\
2 & $0.005 / 50$ & 120 & 3 & 99 \\
3 & $0.0025 / 25$ & 120 & 3 & 99 \\
4 & $0.001 / 10$ & 120 & 6 & 99 \\
5 & $0.0005 / 5$ & 120 & 9 & 99 \\
6 & No Mn & 120 & 12 & Trace \\
$7 \mathrm{~d}$ & $0.005 / 50$ & 120 & 3 & 99
\end{tabular}

aReactions were conducted with acetophenone $(5 \mathrm{mmol}), \mathrm{Mn}$ catalyst $\mathbf{3}, \mathrm{KBHEt}_{3}(1 \mathrm{~mol} \%)$ in 1,4-dioxane $(3 \mathrm{~mL}), P=50$ bar $\mathrm{H}_{2}$

bTotal reaction time and that of $\mathrm{GC}$ analysis, for $\mathrm{H}_{2}$ uptake traces see Supplementary Information.

Information.
cYield determined by GC with dodecane as internal standard.

dReactions was conducted under conditions identical to entry 2 in presence of $2 \mathrm{~mol} \% \mathrm{Hg}$.

hydrogenation can likely proceed over the complex 5 at low catalyst loadings.

The use of the improved activation method allowed carrying out the hydrogenations at lower catalyst loadings and higher reaction temperatures (Table 2). The borohydride activation allowed for a sevenfold reduction of reaction time compared to the best example of alkoxide-promoted hydrogenation described above (Table 2, entry 1 vs. Table 1 , entry 8 ). Furthermore, we could use 3 at $120^{\circ} \mathrm{C}$ with the catalyst loading reduced from 50 to 5 p.p.m. without the loss of catalytic performance (Table 2, entries $2-5)$. Even at 5 p.p.m. loading acetophenone hydrogenation was brought to completion within $9 \mathrm{~h}$ at $120^{\circ} \mathrm{C}$. The homogeneous nature of $\mathrm{Mn}$ catalysis in this reaction was confirmed by control experiments (Table 2, entries 6 and 7). Our kinetic data collected for hydrogenations at $12.5 \mathrm{mmol}$ scale indicated the first order in precatalyst 3 (Fig. 4d) with exceptional TOF $^{\circ}$ values of $>40,000$ $\mathrm{h}^{-1}$ (Fig. 4c) under these reaction conditions.

Substrate scope. Finally, complex 3 proved to be a versatile hydrogenation catalyst (Fig. 5). With mere 50 p.p.m. Mn loading at $120^{\circ} \mathrm{C}$, aromatic ketones $\mathbf{8 a}-\mathbf{8 i}$ were reduced in high to quantitative yield with the exception of sterically demanding tertbutyl phenyl ketone $\mathbf{8 b}$ that was converted with $81 \%$ yield. Milder conditions $\left(80^{\circ} \mathrm{C}\right)$ were used for activated ketones with heterocycles and functional groups $(\mathbf{8 j}-\mathbf{8 1})$, affording corresponding alcohols with $85-99 \%$ isolated yields. Cyclic and linear aliphatic ketones $\mathbf{8 m - 8 q}$ were also hydrogenated with quantitative yields. 


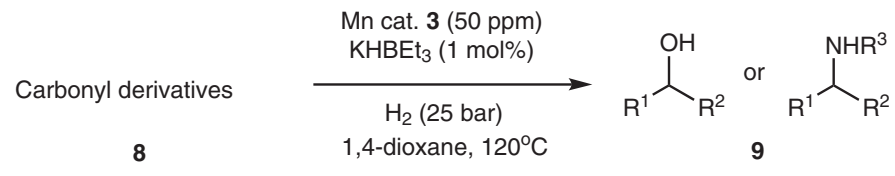<smiles>CCOC(C)(C)C</smiles>

$8 a, 98 \%$<smiles>CC(C)(C)C(=O)c1ccccc1</smiles>

8b, $81 \%$

8c, $99 \%$<smiles>O=C(Cc1ccccc1)c1ccccc1</smiles>

$8 d,>99 \%$<smiles>CC(=O)c1ccc(-c2ccccc2)cc1</smiles>

$8 \mathbf{8},>99 \%$<smiles>CC(=O)c1ccc2ccccc2c1</smiles><smiles>CC(=O)c1ccc2c(c1)OCCO2</smiles><smiles>CC(=O)c1ccc(Br)cc1</smiles><smiles>CC(=O)c1cccnc1</smiles>

8f, $99 \%$ $8 \mathrm{~g},>99 \%[\mathrm{~b}]$<smiles>CC(=O)c1ccc(N)cc1</smiles>
$\mathrm{MeO}_{2} \mathrm{C}$<smiles>CC(=O)c1ccccc1</smiles><smiles>[18O]C1CCCCC1</smiles>

$8 \mathbf{i},>99 \%$<smiles>O=C1CCCc2ccccc21</smiles><smiles>CCCCCCC(C)=O</smiles><smiles>CCCCCC(=O)CC</smiles><smiles>CCCCCC(=O)CCCCC</smiles><smiles>CC(=O)/C=C/c1ccccc1</smiles>

$80^{[c]},>99 \%$

$8 \mathbf{p}^{[c]},>99 \%$

8q, trace

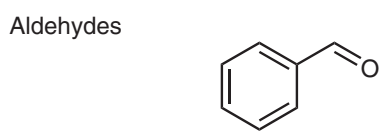
$8 r^{[c]}, 99 \%$<smiles>CN(C)c1ccc(C=O)cc1</smiles>

$8 \mathbf{s}^{[c]},>99 \%$<smiles>O=Cc1ccc(OC(=O)c2ccccc2)cc1</smiles>

$8^{[\mathrm{c}]}, 99 \%$<smiles>O=Cc1ccco1</smiles>

$8 u^{[c]}, 54 \%$

Imines<smiles>C(=N/c1ccccc1)\c1ccccc1</smiles>

$8 \mathbf{v}^{[\mathrm{e}]}, 90 \%$<smiles>Brc1ccc(/N=C/c2ccccc2)cc1</smiles>

$8 \mathbf{w}^{[\mathrm{e}]}, 98 \%[\mathrm{~b}]$<smiles>COc1ccc(/N=C/c2ccccc2)cc1</smiles>

$8 \mathbf{x}^{[e]},>99 \%$

Formic esters<smiles>CCCCCCOC=O</smiles>

$8 y^{[f]},>99 \%$<smiles>CCCCCOC=O</smiles>

$8 z^{[f]},>99 \%$<smiles>CC(C)CCOC=O</smiles>

$8 a^{[f]}, 99 \%$

Fig. 5 Results of catalytic hydrogenation with 3. [a] Typical conditions: 5 mmol substrate, complex 3 (50 p.p.m.), $\mathrm{KBHEt}_{3}(1 \mathrm{~mol} \%)$ in 1,4-dioxane (3 mL), $120^{\circ} \mathrm{C}, P=25$ bar $\mathrm{H}_{2}, 24 \mathrm{~h}$. Yields determined by GC-FID with dodecane internal standard. [b] Isolated yields. [c] Reactions carried out in isopropanol $(3 \mathrm{~mL})$ at $80^{\circ} \mathrm{C}$ instead. [d] The product was corresponding isopropyl ester identified by NMR. [e] 100 p.p.m. of 3 used in isopropanol (3 mL), $120^{\circ} \mathrm{C}$. [f] 200 p.p.m. of $\mathbf{3}$ used.

A noteworthy exception to this set was conjugated $\alpha, \beta$-unsaturated ketone $\mathbf{8 q}$ that was not converted by our catalytic system at appreciable level. In addition to ketones, functionalized aldehydes $(\mathbf{8 r}-\mathbf{8 u})$ and imines $(\mathbf{8 v}-\mathbf{8 x})$ were converted using $50-100$ p.p.m. catalyst loading. Finally, the activity of 3 was sufficient to convert formate esters $(\mathbf{8 y}-\mathbf{8 a a})$ to the corresponding alcohols at 200 p.p.m. catalyst loading.

In summary, our findings highlight a Mn(I)-CNP complex 3 as a truly robust and versatile hydrogenation catalyst. A large part of its performance stems from the unusual coordination behavior of the tridentate ligand in complex 3 that opens up the catalyst activation pathways that are unavailable for conventional $\mathrm{Mn}$ pincers. As an outcome, one obtains a highly stable catalyst tolerating high reaction temperatures, while operating at p.p.m.level loadings. Apart from ketones, the catalytic system allows for the efficient reduction of various unsaturated functional groups, including aldehydes, imines, and formic acid esters in quantitative yields. With the mechanistic analysis of the catalytic action of 3 underway, its performance highlights the high potential of manganese for hydrogenation catalysis. With the introduction of robust mixed donor ligand systems, we anticipate developments in this dynamic field.

\section{Methods}

General procedure for catalytic hydrogenation. Stock solutions of $3(0.01 \mathrm{M})$ were prepared in dioxane solvent. In a typical run, substrate $(5 \mathrm{mmol})$, dioxane 
( $3 \mathrm{~mL}$ ), dodecane internal standard $(56.8 \mu \mathrm{L}, 0.25 \mathrm{mmol})$, base promoter $(0.05 \mathrm{mmol})$, and complex 3 were combined in a $4 \mathrm{~mL}$ glass vials and transferred into a stainless steel autoclave in the glovebox. The system was purged with $\mathrm{N}_{2}(3 \times 8$ bar $)$ and $\mathrm{H}_{2}$ $(1 \times 30 \mathrm{bar})$, pressurized with $\mathrm{H}_{2}$ to specified pressure, and heated to specified temperature. The yields of products were determined by GC or GC-MS.

Kinetic study of acetophenone hydrogenation with Mn catalyst 3 on a large scale. Inside the glovebox, a stock solution of $3(0.0125 \mathrm{M})$ was prepared in 0.875 $\mathrm{mL}$ dioxane, treated with $0.125 \mathrm{~mL}$ of $1 \mathrm{M} \mathrm{KBHEt}_{3}$ solution in THF and stirred for $0.5 \mathrm{~h}$. A $1 \mathrm{~mL}$ syringe was loaded with complex $3(500,250,100$, and $50 \mu \mathrm{L})$ and $\mathrm{KBHEt}_{3}(62.5,93.8,112.5$, and $118.8 \mu \mathrm{L}$ ) in dioxane (total volume $0.7 \mathrm{~mL}$ ), and a $20 \mathrm{~mL}$ syringe was loaded with acetophenone $(1.460 \mathrm{~mL}, 12.5 \mathrm{mmol})$ and dodecane $(113.6 \mu \mathrm{L}, 0.625 \mathrm{mmol})$ in $10 \mathrm{~mL}$ dioxane. Under $\mathrm{N}_{2}$ flow, the substrate syringe was first injected into high pressure stainless steel reactor, in which a glass liner was inserted in advance. The dissolved catalyst was then placed in an injection port and the system was purged with $\mathrm{H}_{2}(3 \times 10 \mathrm{bar})$. The reactor was brought to at $120^{\circ} \mathrm{C}$ at 50 bar $\mathrm{H}_{2}$ pressure with stirring at 500 r.p.m. and reaction was initiated by injecting the catalyst solution. The samples were withdrawn at given time intervals using an autosampler apparatus and analyzed with GC. Data plotted in Fig. 4 of the manuscript.

\section{Data availability}

Data relating to the synthetic procedures, materials and characterization, optimization studies, DFT calculations, $\mathrm{H}_{2}$ consumption traces, and spectral data are available in the Supplementary Information. CCDC-1994375 contains the supplementary crystallographic data for this paper. These data can be obtained free of charge from The Cambridge Crystallographic Data Centre via www.ccdc.cam.ac.uk/data_request/cif. All data generated and analyzed during this study are included in this article and its Supporting Information, and also available from the authors upon reasonable request. Source data are provided with this paper.

Received: 14 May 2020; Accepted: 16 November 2020; Published online: 04 January 2021

\section{References}

1. Rylander, P. N. Catalytic Hydrogenation in Organic Syntheses: Paul Rylander (Academic, New York, 1979)

2. Vries, J. G. d. The Handbook of Homogeneous Hydrogenation (Wiley-VCH Verlag GmbH \& Co. KGaA, Weinheim, Germany, 2007).

3. Arai, N. \& Ohkuma, T. Design of molecular catalysts for achievement of high turnover number in homogeneous hydrogenation. Chem. Rec. 12, 284-289 (2012).

4. Filonenko, G. A., van Putten, R., Hensen, E. J. \& Pidko, E. A. Catalytic (de) hydrogenation promoted by non-precious metals-Co, Fe and $\mathrm{Mn}$ : recent advances in an emerging field. Chem. Soc. Rev. 47, 1459-1483 (2018)

5. Werkmeister, S., Neumann, J., Junge, K. \& Beller, M. Pincer-type complexes for catalytic (De) hydrogenation and transfer (De) hydrogenation reactions: recent progress. Chem. Eur. J. 21, 12226-12250 (2015).

6. Zell, T. \& Milstein, D. Hydrogenation and Dehydrogenation iron pincer catalysts capable of metal-ligand cooperation by aromatization/ dearomatization. Acc. Chem. Res. 48, 1979-1994 (2015).

7. Clarke, M. L. \& Widegren, M. B. in Homogeneous Hydrogenation with NonPrecious Catalysts (ed. Teichert, J. F.). 111-140 (Wiley-VCH Verlag GmbH \& Co. KGaA, Weinheim, Germany, 2020)

8. Chandra, P., Ghosh, T., Choudhary, N., Mohammad, A. \& Mobin, S. M. Recent advancement in oxidation or acceptorless dehydrogenation of alcohols to valorised products using manganese based catalysts. Coord. Chem. Rev. 411, 213-241 (2020).

9. Kallmeier, F. \& Kempe, R. Manganese complexes for (De) hydrogenation catalysis: a comparison to cobalt and iron catalysts. Angew. Chem. Int. Ed. 57, 46-60 (2018)

10. Maji, B. \& Barman, M. K. Recent developments of manganese complexes for catalytic hydrogenation and dehydrogenation reactions. Synthesis $\mathbf{4 9}$, 3377-3393 (2017).

11. Valyaev, D. A., Lavigne, G. \& Lugan, N. Manganese organometallic compounds in homogeneous catalysis: past, present, and prospects. Coord. Chem. Rev. 308, 191-235 (2016).

12. Carney, J. R., Dillon, B. R. \& Thomas, S. P. Recent advances of manganese catalysis for organic synthesis. Eur. J. Org. Chem. 2016, 3912-3929 (2016).

13. Snider, B. B. Manganese (III)-based oxidative free-radical cyclizations. Chem. Rev. 96, 339-364 (1996).

14. Elangovan, S. et al. Selective catalytic hydrogenations of nitriles, ketones, and aldehydes by well-defined manganese pincer complexes. J. Am. Chem. Soc. 138, 8809-8814 (2016).
15. Elangovan, S. et al. Hydrogenation of esters to alcohols catalyzed by defined manganese pincer complexes. Angew. Chem. Int. Ed. 49, 15364-15368 (2016)

16. Freitag, F., Irrgang, T. \& Kempe, R. Mechanistic studies of hydride transfer to imines from a highly active and chemoselective manganate catalyst. J. Am. Chem. Soc. 141, 11677-11685 (2019).

17. Glatz, M., Stöger, B., Himmelbauer, D., Veiros, L. F. \& Kirchner, K. Chemoselective hydrogenation of aldehydes under mild, base-free conditions: manganese outperforms rhenium. ACS Catal. 8, 4009-4016 (2018).

18. Kaithal, A., Hölscher, M. \& Leitner, W. Catalytic hydrogenation of cyclic carbonates using manganese complexes. Angew. Chem. Int. Ed. 57, 13449-13453 (2018)

19. Kumar, A., Janes, T., Espinosa-Jalapa, N. A. \& Milstein, D. Manganese catalyzed hydrogenation of organic carbonates to methanol and alcohols. Angew. Chem. Int. Ed. 57, 12076-12080 (2018).

20. Li, $\mathrm{H}$. et al. Rhenium and manganese complexes bearing amino-bis (phosphinite) ligands: synthesis, characterization, and catalytic activity in hydrogenation of ketones. Organomet 37, 1271-1279 (2018).

21. Papa, V. et al. Efficient and selective hydrogenation of amides to alcohols and amines using a well-defined manganese-PNN pincer complex. Chem. Sci. 8, 3576-3585 (2017)

22. Weber, S., Stöger, B., Veiros, L. F. \& Kirchner, K. Rethinking basic concepts: hydrogenation of alkenes catalyzed by bench-stable alkyl Mn (I) complexes. ACS Catal. 9, 9715-9720 (2019).

23. Wei, D. et al. Hydrogenation of carbonyl derivatives catalysed by manganese complexes bearing bidentate pyridinyl-phosphine ligands. Adv. Synth. Catal. 360, 676-681 (2018).

24. Zou, Y.-Q. et al. Highly selective, efficient deoxygenative hydrogenation of amides catalyzed by a manganese pincer complex via metal-ligand cooperation. ACS Catal. 8, 8014-8019 (2018).

25. Fertig, R. et al. Manganese-catalyzed and base-switchable synthesis of amines or imines via borrowing hydrogen or dehydrogenative condensation. ACS Catal. 8, 8525-8530 (2018).

26. Zhang, L. et al. Lutidine-based chiral pincer manganese catalysts for enantioselective hydrogenation of ketones. Angew. Chem. Int. Ed. 58, 4973-4977 (2019).

27. Ling, F. et al. Highly enantioselective synthesis of chiral benzhydrols via manganese catalyzed asymmetric hydrogenation of unsymmetrical benzophenones using an imidazole-based chiral PNN tridentate ligand. Org. Lett. 21, 3937-3941 (2019).

28. Kallmeier, F., Irrgang, T., Dietel, T. \& Kempe, R. Highly active and selective manganese $\mathrm{C}=\mathrm{O}$ bond hydrogenation catalysts: the importance of the multidentate ligand, the ancillary ligands, and the oxidation state. Angew. Chem. Int. Ed. 55, 11806-11809 (2016).

29. Espinosa-Jalapa, N. A. et al. Manganese-catalyzed hydrogenation of esters to alcohols. Chem. Eur. J. 23, 5934-5938 (2017).

30. Zhang, L. et al. Lutidine-based chiral pincer manganese catalysts for enantioselective hydrogenation of ketones. Angew. Chem. Int. Ed. 58, 4973-4977 (2019)

31. Putten, R. V. et al. Non-pincer-type manganese complexes as efficient catalysts for the hydrogenation of esters. Angew. Chem., Int. Ed. 56, 7531-7534 (2017).

32. Weber, S., Stöger, B. \& Kirchner, K. Hydrogenation of nitriles and ketones catalyzed by an air-stable bisphosphine Mn (I) complex. Org. Lett. 20, 7212-7215 (2018)

33. Garduño, J. A. \& García, J. J. Non-pincer Mn (I) organometallics for the selective catalytic hydrogenation of nitriles to primary amines. ACS Catal. $\mathbf{9}$, 392-401 (2018).

34. Buhaibeh, R. et al. Phosphine-NHC manganese hydrogenation catalyst exhibiting a non-classical metal-ligand cooperative $\mathrm{H}_{2}$ activation mode. Angew. Chem. Int. Ed. 58, 6727-6731 (2019).

35. Putten, R. et al. Efficient and practical transfer hydrogenation of ketones catalyzed by a simple bidentate Mn-NHC complex. ChemCatChem 11, 1-5 (2019).

36. Becker, E. et al. Novel $[2+2+1]$ cyclotrimerization of alkynes mediated by bidentate cyclopentadienyl-phosphine ruthenium complexes. Organometallics 22, 3164-3170 (2003).

37. Eliasson, S. H. H. \& Jensen, V. R. Benefit of a hemilabile ligand in deoxygenation of fatty acids to 1-alkenes. Faraday Discuss. 220, 231-248 (2019).

38. Foerstner, J., Kakoschke, A., Wartchow, R. \& Butenschön, H. Reactions of cyclopropenone derivatives with a cyclopentadienylcobalt (I) chelate: formation of a cobaltacyclobutenone and a transformation of 2,2dimethoxycyclopropenone to methyl acrylate at cobalt. Organometallics 19, 2108-2113 (2000).

39. Müller, C., Lachicotte, R. J. \& Jones, W. D. Catalytic C - C bond activation in biphenylene and cyclotrimerization of alkynes: increased reactivity of $\mathrm{P}, \mathrm{N}$ versus P, P-substituted nickel complexes. Organometallics 21, 1975-1981 (2002). 
40. Müller, C., Lachicotte, R. J. \& Jones, W. D. Chelating P, N versus P, P ligands: differing reactivity of donor-stabilized $\mathrm{Pt}\left(\eta^{2}-\mathrm{PhC}: \mathrm{CPh}\right)$ complexes toward diphenylacetylene. Organometallics 21, 1118-1123 (2002).

41. Wei, C. et al. Aluminum complexes bearing bidentate amido-phosphine ligands for ring-opening polymerization of $\varepsilon$-caprolactone: steric effect on coordination chemistry and reactivity. Organometallics 38, 3816-3823 (2019).

42. Braunstein, P. \& Naud, F. Hemilability of hybrid ligands and the coordination chemistry of oxazoline-based systems. Angew. Chem. Int. Ed. 40, 680-699 (2001).

43. Grützmacher, H. Cooperating ligands in catalysis. Angew. Chem. Int. Ed. 47, 1814-1818 (2008).

44. Müller, C., Vos, D. \& Jutzi, P. Results and perspectives in the chemistry of side-chain-functionalized cyclopentadienyl compounds. J. Organomet. Chem. 600, 127-143 (2000).

45. Krut'ko, D. P., Borzov, M. V., Veksler, E. N., Churakov, A. V. \& Mach, K. Crystal structures and solution dynamics of monocyclopentadienyl titanium (IV) complexes bearing pendant ether and phosphanyl type functionalities. Polyhedron 22, 2885-2894 (2003).

46. Yong, L., Hofer, E., Wartchow, R. \& Butenschön, H. Oxidative addition of hydrosilanes, hydrogermane, and hydrostannane to cyclopentadienylcobalt (I) bearing a pendant phosphane ligand: cyclopentadienylhydridocobalt (III) chelate complexes with silyl, germyl, and stannyl ligands. Organometallics 22, 5463-5467 (2003).

47. Yu, X.-J. et al. Hemilabile N-heterocyclic carbene (NHC)-nitrogen-phosphine mediated $\mathrm{Ru}$ (II)-catalyzed $\mathrm{N}$-alkylation of aromatic amine with alcohol efficiently. Catal. Commun. 95, 54-57 (2017).

48. Chakraborty, S. et al. Manganese-catalyzed N-formylation of amines by methanol liberating $\mathrm{H}_{2}$ : a catalytic and mechanistic study. Angew. Chem. Int. Ed. 56, 4229-4233 (2017).

49. Kumar, A. et al. Direct synthesis of amides by dehydrogenative coupling of amines with either alcohols or esters: manganese pincer complex as catalyst. Angew. Chem. Int. Ed. 56, 14992-14996 (2017).

\section{Acknowledgements}

This research was supported by the European Research Council under the European Union's Horizon 2020 research and innovation program (grant agreement no. 725686). G.A.F. acknowledges NWO for an individual Veni grant. All authors acknowledge SURFsara for computational resources and BT Mass Spectrometry Facility at TU Delft for HRMS measurement.

\section{Author contributions}

W.Y., G.A.F., and E.A.P. wrote the manuscript; W.Y. designed, conducted the experiments, and analyzed the data; I.Y.C. performed the DFT calculation; R.K.A.S. conducted part of kinetics studies; M.W. and C.M. performed crystal structure determination and analysis; G.A.F. and E.A.P. supervised the research.

\section{Competing interests}

The authors declare no competing interests.

\section{Additional information}

Supplementary information is available for this paper at https://doi.org/10.1038/s41467020-20168-2.

Correspondence and requests for materials should be addressed to G.A.F. or E.A.P.

Peer review information Nature Communications thanks Rhett Kempe and the other, anonymous, reviewer(s) for their contribution to the peer review of this work. Peer reviewer reports are available.

Reprints and permission information is available at http://www.nature.com/reprints

Publisher's note Springer Nature remains neutral with regard to jurisdictional claims in published maps and institutional affiliations.

(c) (i) Open Access This article is licensed under a Creative Commons Attribution 4.0 International License, which permits use, sharing, adaptation, distribution and reproduction in any medium or format, as long as you give appropriate credit to the original author(s) and the source, provide a link to the Creative Commons license, and indicate if changes were made. The images or other third party material in this article are included in the article's Creative Commons license, unless indicated otherwise in a credit line to the material. If material is not included in the article's Creative Commons license and your intended use is not permitted by statutory regulation or exceeds the permitted use, you will need to obtain permission directly from the copyright holder. To view a copy of this license, visit http://creativecommons.org/ licenses/by/4.0/.

(C) The Author(s) 2021 